\title{
T Cell-Mediated Chronic Inflammatory Diseases Are Candidates for Therapeutic Tolerance Induction with Heat Shock Proteins
}

\author{
Ariana Barbera Betancourt ${ }^{\dagger}$, Qingkang Lyu, Femke Broere, Alice Sijts, \\ Victor P. M. G. Rutten and Willem van Eden*
}

Faculty of Veterinary Medicine, Department of Infectious Diseases and Immunology, Utrecht University, Utrecht, Netherlands

\section{OPEN ACCESS}

Edited by:

Masaaki Murakami,

Hokkaido University, Japan

Reviewed by:

Gabriele Multhoff,

Technische Universität München,

Germany

Hideki Ogura,

Yale University, United States

${ }^{*}$ Correspondence:

Willem van Eden

w.vaneden@uu.nl

tPresent address:

Ariana Barbera Betancourt, Department of Medicine, University of Cambridge, United Kingdom

Specialty section:

This article was submitted to Inflammation,

a section of the journal

Frontiers in Immunology

Received: 26 June 2017 Accepted: 11 October 2017 Published: 26 October 2017

Citation:

Barbera Betancourt A, Lyu Q, Broere F, Sijts A, Rutten VPMG and van Eden W (2017) T Cell-Mediated Chronic Inflammatory Diseases Are Candidates for Therapeutic Tolerance Induction with Heat Shock Proteins.

Front. Immunol. 8:1408. doi: 10.3389/fimmu.2017.01408
Failing immunological tolerance for critical self-antigens is the problem underlying most chronic inflammatory diseases of humans. Despite the success of novel immunosuppressive biological drugs, the so-called biologics, in the treatment of diseases such rheumatoid arthritis (RA) and type 1 diabetes, none of these approaches does lead to a permanent state of medicine free disease remission. Therefore, there is a need for therapies that restore physiological mechanisms of self-tolerance. Heat shock proteins (HSPs) have shown disease suppressive activities in many models of experimental autoimmune diseases through the induction of regulatory $T$ cells (Tregs). Also in first clinical trials with HSP-based peptides in RA and diabetes, the induction of Tregs was noted. Due to their exceptionally high degree of evolutionary conservation, HSP protein sequences (peptides) are shared between the microbiota-associated bacterial species and the self-HSP in the tissues. Therefore, Treg mechanisms, such as those induced and maintained by gut mucosal tolerance for the microbiota, can play a role by targeting the more conserved HSP peptide sequences in the inflamed tissues. In addition, the stress upregulated presence of HSP in these tissues may well assist the targeting of the HSP induced Treg specifically to the sites of inflammation.

Keywords: heat shock proteins, tolerance, $\mathrm{T}$ regulatory cells, rheumatoid arthritis, inflammatory eye diseases, diabetes mellitus, type 1

In many cases, chronic inflammatory diseases are autoimmune diseases that are caused by a loss of tolerance to self-antigens due to inappropriate activation of the immune system. Collectively, autoimmune diseases affect $4-5 \%$ of the population, being females affected with a higher incidence than males (3:1 ratio) (1).

Genome-wide association studies have underscored the genetic association of the major histocompatibility complex (MHC) region with autoimmune diseases, in which case various predisposing alleles have been found $(2,3)$. The main function of MHC molecules is to present processed peptides for the recognition of antigen-specific $\mathrm{T}$ cells. And such $\mathrm{T}$ cells have the capacity to damage healthy tissues when they are not tightly controlled. The exact mechanisms triggering autoimmune diseases are unknown, but the presence of pro-inflammatory $\mathrm{T}$ cells in target organs as well as the strong link with MHC loci highlights the important role for adaptive immune responses in their development. The most accepted hypothesis proposes that for the initiation of an autoimmune disease, 
an immune response with pro-inflammatory characteristics needs to be directed against specific tissue antigens in genetically susceptible individuals. Regulatory mechanisms exist in the periphery to control such effector responses to avoid excessive tissue damage (4). Mechanisms include the following: regulatory $\mathrm{T}$ cells (Tregs), direct inactivation of effector $\mathrm{T}$ (Teff) cells by induction of anergy or apoptosis and activities mediated by tolerogenic antigen-presenting cells (APCs). However, there is an increasing understanding that pro-inflammatory responses directed to self-antigens become chronic in autoimmune diseases because regulatory mechanisms fail to control them.

\section{PERIPHERAL TOLERANCE MECHANISMS CD4 $^{+}$CD25 $^{\text {high }}$ Foxp3 $^{+}$}

$\mathrm{CD} 4{ }^{+} \mathrm{CD} 25^{\text {high }} \mathrm{FoxP} 3^{+}$Tregs can prevent autoimmune diseases by maintaining the tolerance to self-antigens. FoxP3 constitutes the most specific marker for these cells and is to some extent indispensable to develop a Treg phenotype and for their suppressive function (5). The development of autoimmune diseases when $\mathrm{CD} 4{ }^{+} \mathrm{CD} 25^{+}$cells are depleted in normal rodents or when rodents and humans have mutated FoxP3 genes highlights the role of Tregs in the prevention of such diseases $(6,7)$. As illustrated in Figure 1, when activated by their cognate antigen, Treg cells display a broad range of suppressive mechanisms, which endow them with the ability to control immune responses. The potential of controlling $\mathrm{T}$ - and B-cell responses with different specificities as well as the modulation of the maturation status of APCs by Tregs makes them attractive targets for the development of therapeutic strategies. Apart from $\mathrm{CD} 4{ }^{+} \mathrm{CD} 25^{\text {high }}{ }$ oxp $3^{+}$Tregs, there are several subsets of $\mathrm{CD}^{+} \mathrm{T}$ cells that are able to downregulate $\mathrm{CD} 4^{+}$ $\mathrm{T}$-cell effector responses by different mechanisms including the induction of anergy in APCs and T cells as well as the secretion of anti-inflammatory cytokines (8). CD8 ${ }^{+} \mathrm{CD} 28^{-}{ }^{-}$oxp $3^{+}$Treg cells are probably the subset best characterized (9). The activation of these cells is antigen specific [major histocompatibility complex (MHC)-I class-restricted], and their suppressor mechanism

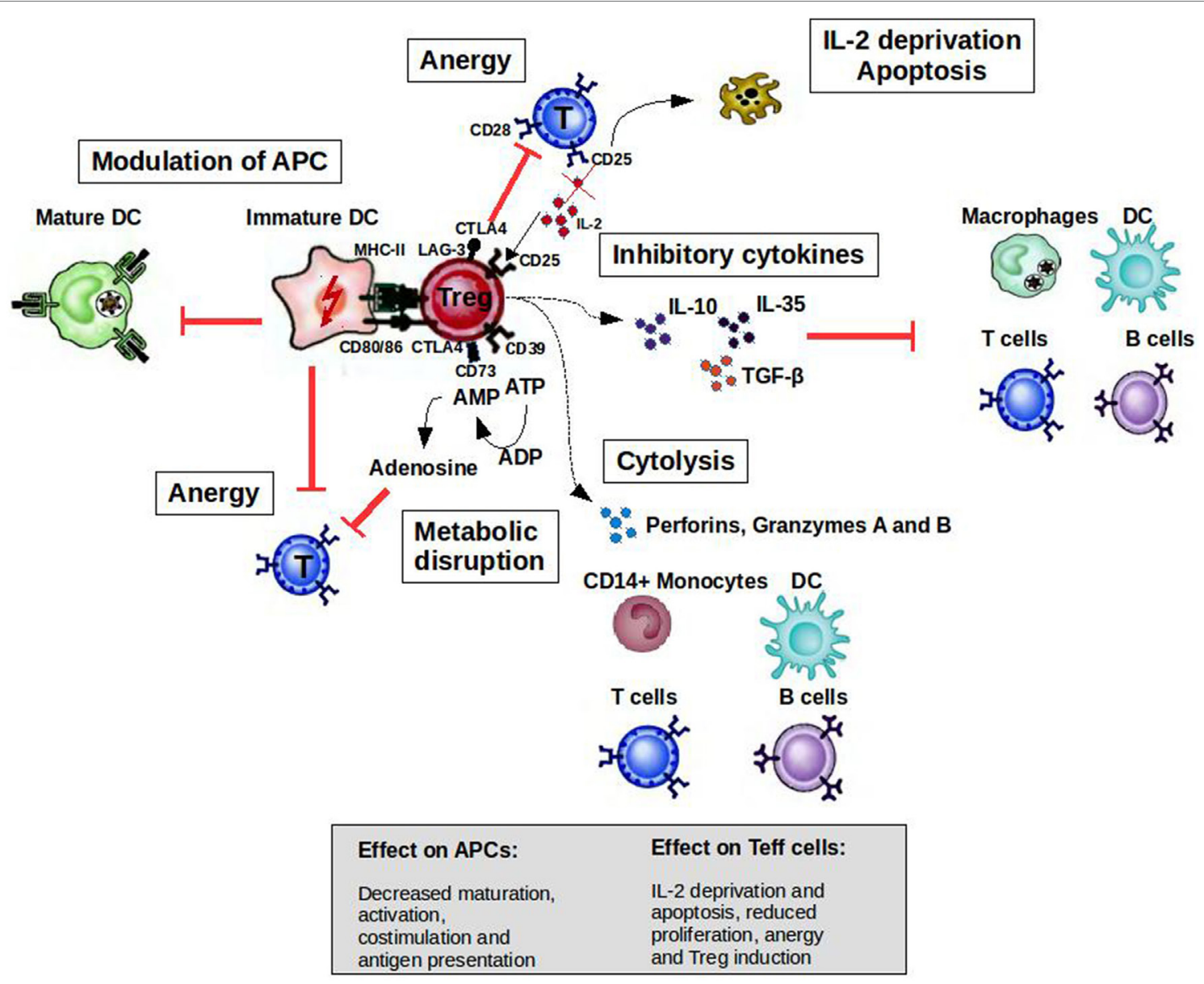

FIGURE 1 | Mechanisms of suppression by Treg cells to control immune responses. A broad range of molecular mechanisms contribute to the suppressive function of Tregs. Mechanisms include the following: apoptosis/cytolysis (IL-2 deprivation, granzyme A/B, perforins); antigen-presenting cell (APC) modulation (CTLA4, LAG-3); inhibitory cytokines (IL-10, IL-35, and TGF- $\beta$ ); and metabolic disruption (CD73/39 and ATP/adenosine mechanism). Abbreviations: CTLA4, cytotoxic T lymphocyte-associated antigen 4; DC, dendritic cell; CD, cluster of differentiation; IL, interleukin; Treg cell, regulatory T cell; LAG-3, Iymphocyte activation gene 3; TGF, transforming growth factor; $\mathrm{MHC}$, major histocompatibility complex. 
involves the induction of a tolerogenic phenotype in APCs by the increased expression of immunoglobulin-like transcript 3 (ILT3) and ILT4. ILT3 and ILT4 suppress the activation of nuclear factor$\mathrm{\kappa B}$ mediated by CD40, which in turn reduces the transcription of co-stimulatory molecules such as CD80 and CD86 (9-11). These tolerogenic APCs in turn promote an anergic phenotype on naive $\mathrm{CD}^{+}$and $\mathrm{CD} 8^{+} \mathrm{T}$ cells, which could acquire similar regulatory functions spreading the induction of tolerance (10).

However, some studies have shown that patients with autoimmune diseases have less effective or fewer $\mathrm{CD} 4{ }^{+} \mathrm{CD} 25^{\text {high }} \mathrm{Foxp} 3^{+}$ Treg cells compared with healthy individuals [reviewed in Ref. (12)]. Numbers and/or function of $\mathrm{CD}^{+}$Tregs have been also found to be defective in animal models of autoimmunity and in patients (13). Defects in the capacity of Teff cells to be controlled by Tregs have also been found in the context of autoimmune diseases (12). Collectively, these findings suggest that Treg malfunction might be a factor promoting the development or chronicity of autoimmune diseases. Therefore, approaches to expand regulatory populations in autoimmune diseases have therapeutic potential $(14,15)$.

\section{Anergy}

$\mathrm{T}$ cells are activated when their T-cell receptors (TCRs) recognize antigenic peptides presented by MHC molecules expressed on the surface of APCs. Secondary signals like the one provided by CD28 expressed by T cells and B7.1 (CD80) or B7.2 (CD86) expressed by APCs are essential to initiate IL-2 production and $\mathrm{T}$-cell proliferation. However, the activation of $\mathrm{T}$ cells without second signals induces a state of anergy where these clones are not able to respond to antigenic stimulus because they cannot produce IL-2. Cytotoxic T lymphocyte-associated antigen-4 (CTLA4) is a cell surface molecule related to CD28 that has the ability to block CD28-dependent $\mathrm{T}$ cell activation (16). The critical role of this molecule in controlling T-cell activation and maintaining peripheral tolerance was supported by the development of a massive lymphoproliferative disorder and autoimmune disease being fatal by 3-4 weeks of age in CTLA-4-deficient mice (17). Activated $\mathrm{T}$ cells transiently increase the expression of CTLA4, which is important to limit the expansion of activated $\mathrm{T}$ cells during an immune response. This cell surface molecule is expressed constitutively by Tregs endowing them with the potential to control T-cell activation through CD28 blockade (Figure 1). The inhibition of the CD28-dependent T cell activation has been used as a therapeutic tool for several autoimmune diseases. The blockade of the CD28 pathway with CTLA-Ig in animal models of autoimmune diseases prevented the progression of the disease [reviewed in Ref. (18)]. Abatacept (CTLA4-Ig) has been approved by the FDA for use in rheumatoid arthritis (RA) patients with an inadequate response to one or more of the disease-modifying antirheumatic drugs.

\section{Apoptosis}

Apoptotic cell death is another important regulatory mechanism operating in the thymus and periphery to delete self-reactive $\mathrm{T}$ cells or activated pathogenic T-cell clones, respectively. During the development of $\mathrm{T}$ cells in the thymus, clones bearing autoreactive TCRs are eliminated by apoptosis in a process known as negative selection. However, T cells with potential autoreactive receptors escape to the periphery where these clones should be kept in check by regulatory mechanisms such as Tregs, anergy, or deletion. In the periphery, activated $\mathrm{T}$ cells express death receptors belonging to the tumor necrosis factor (TNF) family (e.g., Fas/ Fas-ligand) making them susceptible to activation-induced cell death (AICD) $(19,20)$. Memory T cells, Tregs, and Th2 cells are less susceptible than Th1 cells to $\operatorname{AICD}(21,22)$, allowing the polarization of the immune response to protective responses (Th2/Treg) in the periphery. On the other hand, by inducing IL-2 deprivation and secreting perforins and granzymes, Tregs at the site of inflammation increase the susceptibility of Teff cells and other cells such as B cells and monocytes to cell death $(23,24)$.

\section{Tolerogenic APC}

Tolerogenic APCs present antigens to T cells but since they display low numbers of co-stimulatory molecules such as CD80, CD86, and CD40, antigen presentation leads to T-cell anergy (25). Tolerogenic APCs can be induced and enhanced using different compounds such as rapamycin, corticosteroids, interleukin-10 (IL-10), and transforming growth factor beta 1 (26). Several studies have shown the therapeutic effect of tolerogenic APCs induced ex vivo in experimental animal models [reviewed in Ref. $(27,28)]$. Treg cells can also modulate the maturation status of APCs. For example, these cells can decrease the expression of co-stimulatory molecules on APC affecting their capacity to activate T cells (29). In addition, ligation of CTLA4 to CD80 and CD86 induces APC to express an immunosuppressive molecule (indoleamine 2,3-dioxygenase), which is able to abolish T-cell activation (30, 31). Lymphocyte activation gene 3 (LAG-3) is another molecule expressed by Tregs that could affect APC function. This is a CD4 homolog with a high affinity for MHC class II molecules. The binding of LAG-3 to MHC class II induces an inhibitory signaling pathway, which leads to the inhibition of APC maturation (Figure 1) (32).

\section{MHC-ASSOCIATED DISEASES ARE T CELL-MEDIATED AND POSSIBLE TARGETS FOR INDUCTION OF HEAT SHOCK PROTEIN (HSP)-DRIVEN THERAPEUTIC TOLERANCE}

The strong link of autoimmune diseases with MHC loci and the presence of pro-inflammatory $\mathrm{T}$ cells in target organs highlight the important role for adaptive immune responses in their development. In such cases, therapeutic tolerance may become established through the induction of Tregs with bystander regulatory activities leading to the inhibition or modulatory skewing of these pro-inflammatory self-antigen-specific $\mathrm{T}$ cells. Examples of MHC-associated, primarily T-cell driven autoimmune diseases are RA, type 1 diabetes (T1D), and several eye diseases.

\section{Rheumatoid Arthritis}

Rheumatoid arthritis is a chronic inflammatory disease characterized by joint inflammation and synovial hyperplasia, which leads to cartilage and bone destruction (33). 
The HLA-DRB1 gene has been associated with the susceptibility of this disease, especially with the shared epitope (SE) coding alleles (HLA-DRB $1{ }^{\star} 0401,{ }^{\star} 0404,{ }^{\star} 0405,{ }^{\star} 0408,{ }^{\star} 0101$, ${ }^{\star} 0102,{ }^{\star} 1402$, and $\left.{ }^{\star} 1001\right)$. The $\mathrm{SE}$ is a five amino-acid sequence motif found in residues $70-74$ of the HLA-DR $\beta$ chain that encodes a conserved positively charged residue at position 71 (34). The latter seems to guide the nature of the amino acid that can be accommodated in the P4 pocket of these HLA-DR molecules. Although the susceptibility of this disease appears to be determined genetically, the onset might depend on other factors such as environmental, epigenetic or posttranslational events factors (35).

As expected by the strong association of HLA-DRB1 and $\mathrm{RA}, \mathrm{CD} 4^{+} \mathrm{T}$ cells are enriched in synovia of these patients and seem to play a critical role in the perpetuation of inflammation [reviewed in Ref. (36)]. Susceptibility to RA has also been linked to other pathways implicated in the activation of $\mathrm{T}$ cells, such as PTPN22, PTPN2, CTLA4, IL2RA, IL-2RB, among others [reviewed in Ref. (29)]. Specifically, a CD4 ${ }^{+} \mathrm{T}$ cell subset that produces IL-17, 21, 22, and TNF- $\alpha$ has been in the center of the attention in recent years. Emerging data have suggested that active RA might result from an imbalance between defective Tregs and pro-inflammatory Th17 cells (37-39). Nevertheless, the mechanisms governing such imbalance that could contribute to RA chronicity have remained unclear.

Tumor necrosis factor- $\alpha$ has been shown to be the master element of inflammation in RA (40). Consequently, the blockade of this cytokine has emerged as the main tool for its treatment. Although the exact mechanism underlying clinical effects of anti-TNF- $\alpha$ therapy in patients is not completely understood it is apparent that it can have an effect on other pathways associated with tolerance (41). For instance, it has been reported that the treatment with infliximab increases the percentage of $\mathrm{CD} 4{ }^{+} \mathrm{CD} 25^{+}$Tregs in RA patients who responded to therapy (42). Further studies showed that infliximab induced a distinct Treg population in vitro that could compensate the compromised Tregs detected in RA (43). Despite excellent results in patients responding to anti-TNF- $\alpha$ therapy, there is an increased susceptibility to serious adverse effects including: infectious diseases, malignancies and demyelination (44). In addition, only partial responses are achieved with this treatment and a continuous treatment is required.

\section{Diabetes Mellitus Type 1}

Pancreatic $\beta$ cells producing insulin are the targets for antigenspecific $\mathrm{T}$ cells in T1D. Epidemiologic studies suggest that the incidence of this disease is rising (45). The updated estimates of the incidence (20.04 per 100,000 per year) and prevalent cases $(129,350)$ of T1D in children 0-14 years old in Europe for 2013 (46) reflect an increasing trend of $3-4 \%$ per annum during the past 20 years $(47)$.

HLA-DRB $1^{\star} 0401-\mathrm{DQB} 1^{\star} 0302$ and HLA-DRB1 ${ }^{\star} 0301-$ DQB $1^{\star} 0201$ have been associated with T1D susceptibility whereas the haplotypes HLA-DRB1 ${ }^{\star} 1501$ and HLA-DQA1 ${ }^{\star} 0102$ DQB $1^{\star} 0602$ confer resistance (48). However, most people bearing the haplotypes associated with the greatest susceptibility do not develop the disease. In addition, despite the finding of islet-specific $\mathrm{T}$ cells in the blood of healthy individuals, one study showed that these cells secrete IL-10 instead of interferon gamma (IFN- $\gamma$ ) (49), indicating that regulatory mechanisms should fail to develop T1D. Indeed, there is evidence supporting that regulation is impaired in this disease, where patients seem to have a decreased Treg suppressive functionality compared with non-diabetic controls $(50,51)$.

The exact mechanism by which $\beta$ cells are destroyed in the pancreas is not fully understood, but genetic and environmental factors appear to predispose individuals with defective regulatory mechanisms to develop the disease. Similar to other chronic inflammatory diseases, T1D onset requires $\mathrm{CD}^{+}$and $\mathrm{CD}^{+}$ $\mathrm{T}$ cells [reviewed in Ref. (52)]. The latter has been demonstrated in experiments in which the precipitation or prevention of diabetes was achieved in the non-obese mice model by transfer or elimination of $\mathrm{CD} 4^{+}$or $\mathrm{CD} 8^{+} \mathrm{T}$ cells, respectively. Both cell types are able to infiltrate the pancreatic islets in mice and humans and are considered to be the final executors of the destruction of insulin-producing $\beta$ cells (52). $\mathrm{CD}^{+}$and $\mathrm{CD}^{+} \mathrm{T}$ cells can induce the death of pancreatic $\beta$ cells. However, as $\beta$ cells only express HLA-class I, direct cytotoxicity can be only mediated by $\mathrm{CD}^{+}$ $\mathrm{T}$ cells able to recognize appropriated peptides displayed on $\beta$-cell class I molecules. $\mathrm{CD}^{+} \mathrm{T}$ cells are able to kill $\beta$ cells through different mechanisms including granzyme B and perforins, proinflammatory cytokines, and/or Fas/FasL interactions (52).

No drugs have been approved to halt the autoimmune process that causes the destruction of $\beta$ cells in T1D (53). The main goals are the induction of a residual $\beta$-cell function. Different approaches to treat this disease have been used so far [reviewed in Ref. (54)]. One of the therapeutic approaches showing promise in T1D is the use of anti-CD3 monoclonal antibodies that have been shown to interfere antigen-specific $\mathrm{T}$ cell activation. However, after promising clinical trials (phase 1 and 2) in T1D patients with a recent onset, phase 3 trials fail to meet primary endpoints $(55,56)$.

\section{MHC-Associated Inflammatory Eye Diseases}

Various studies have confirmed that eye diseases, such as idiopathic uveitis (57), birdshot retinochoroidopathy (BSR) (58), and sympathetic ophthalmia (59), have an association with MHC. Uveitis is the most common form of inflammatory eye disease and one of the leading causes of visual impairment and blindness. The association of the MHC class I molecule HLA-B27 with uveitis was first noted in 1973 (60). The precise molecular and pathogenic mechanisms behind the association between uveitis and HLA-B27 have remained unclear. HLA-B27 encompasses around 105 known subtypes (HLA-B ${ }^{\star} 27: 01$ to HLA-B ${ }^{\star} 27: 106$ thus far identified) that are encoded by 132 alleles (61). HLA-B27 subtypes have a varied prevalence in different races and regions of the world. HLA-B ${ }^{\star} 2705$ and $B^{\star} 2702$ are the main HLA-B27 subtypes in northern Europe, whereas HLA-B ${ }^{\star} 2704$ and $B^{\star} 2706$ are the most widespread subtype among Asian populations (62). A study from China found that among northern Chinese people, ankylosing spondylitis (AS) patients with $\mathrm{B}^{\star} 2704$ have a stronger risk of developing uveitis than those with $\mathrm{B}^{\star} 2705$ in Ref. (63). Conversely, a Japanese study showed that HLA-B27 anterior 
uveitis (AAU) patients with the $\mathrm{B}^{\star} 2704$ subtype seemed to be less susceptible than patients with $B^{\star} 2705$ (64). This suggests that ${\text { HLA }-B^{\star} 2704 \text { and HLA-B }}^{\star} 2705$ may be the most prevalent HLAB27 subtypes, with observed conflicting results on the role of this molecule in AAU caused by different races and regions, genetic background, or environmental factors. Remarkably, the majority of individuals who carry susceptibility conferring HLA subtypes never develop uveitis or other systemic autoimmune disease, implying that HLA-B27 is a genetically predisposing factor for uveitis but that other genetic or environmental factors contribute to the development of uveitis. HLA-B27-associated uveitis is also closely related to other systemic autoimmune syndromes, such as AS and systemic sarcoidosis. Several studies have shown that HLA-B27-positive AS patients are more susceptible to uveitis than HLA-B27-negative patients $(65,66) .20-30 \%$ of patients with sarcoidosis were affected by uveitis (67).

Except for uveitis, also specific other ocular inflammatory diseases show a strong association with HLA. BSR and idiopathic retinal vasculitis are associated with HLA-A29 (68), with HLA$A^{\star} 29.01$ and HLA-A ${ }^{\star} 29.02$ representing the most common A29 subtypes found in BSR patients (69). The HLA-A*29.01 subtype is more frequent among Asians, whereas HLA-A ${ }^{\star} 29.02$ is more common among Caucasians (70). In addition, Behcet's disease (BD) is an inflammatory disease affecting multiple organs that also include a relapsing and remitting pan-uveitis, which is strongly associated with HLA-B ${ }^{\star} 51$ (71). HLA-B5101 is the predominant subtype associated with BD in Japanese and Iranian patients. The association of HLA-B ${ }^{\star} 5108$ and BD was also found in Greek and Spanish patients. A study of Israeli showed that HLA-B ${ }^{\star} 52$ may also be associated with BD (72).

In humans, more and more evidence reveals that cytokines produced by autoreactive Teff cell play a pivotal role in the pathogenesis of autoimmune uveitis. Early studies suggested that the imbalance of anti- and pro-inflammatory Th2 and Th1 subsets is responsible for the pathology of uveitis. However, in recent studies, emphasis was laid on Th17 and $\mathrm{CD} 4{ }^{+} \mathrm{CD} 25^{+} \mathrm{FoxP} 3^{+} \mathrm{T}$ regulatory cells, which produce IL-17 and IL-10, respectively. The ratio of Th17/Treg was distinctly increased at the progression of uveitis in patients and in experimental autoimmune uveitis (EAU) disease models $(73,74)$, and imbalance of Treg cells over Th17 cells was observed at the recovery phase of EAU (73). Th1 cells play central roles in early phase of uveitis, whereas Th17 cells act in the late phase of uveitis (75), Treg and inducible Treg cells suppress both Th1 and Th17 cell responses by counterbalancing pro-inflammatory activities of these $\mathrm{T}$ cells. This implies that increasing the number of Treg cells may be a promising and safe way to control MHC-associated eye diseases.

\section{HSP AND THE INDUCTION OF THERAPEUTIC TOLERANCE}

\section{HSP Proteins or Peptides As Inducers of Tregs}

Initial studies reported that several HSP families were able to induce both pro-inflammatory and anti-inflammatory effects. Pro-inflammatory cytokine production mediated by HSP70 appears to be linked to the activation of toll-like receptor 2 (TLR2) and TLR4 signaling pathways on innate immune cells (76, 77). Pathogen-associated molecular patterns such as lipopolysaccharide or other proteins present in recombinant HSP produced in bacteria have been suggested to be responsible for the observed pro-inflammatory effects [reviewed in Ref. (78)]. In line with this idea, HSPs often fail to induce an inflammatory effector response in highly purified preparations $(79,80)$. On the contrary, other studies using non-recombinant Hsp70, boiling treatments (which cause the degradation of HSP) or antibiotics have led to the conclusion that HSPs are responsible for the activation of innate immune cells as well as T cells through TLR signaling pathways $(81,82)$. It seems that whether these proteins have an activating or immunosuppressive role depends on several factors including their local concentration, the nature of the HSP itself (self or microbial), among others [reviewed in Ref. (83)]. In the context of autoimmune diseases, HSP proteins have been considered as target molecules involved in their pathogenesis in part because they become highly available at sites of inflammation (83). The other main reason is the high homology between species whereby microbial HSPs can active immune responses that can be cross-reactive with self-HSPs, which in theory could provoke autoimmunity. However, autoreactivity to self-HSPs has been also found in healthy individuals $(84,85)$, which means that these proteins are under a tight regulation network. The latter also means that autoreactivity to self-HSPs is not a synonym of autoimmunity. In fact, self-HSP reactivity appears to be a physiological mechanism for controlling the inflammatory process (86). In this regard, several studies in mice and humans support the fact that HSP, and specially conserved epitopes have the potential for attenuating rather than triggering inflammatory responses $(87,88)$.

The initial indication of a possible role of HSP in the induction of therapeutic tolerance was obtained in the model of adjuvant arthritis in rats. $\mathrm{T}$ cells collected from diseased animals were found to respond to mycobacterial HSP60 (89). When the recombinant mycobacterial HSP60 protein was used for immunizations, no arthritis was seen to develop. Interestingly, induction of adjuvant arthritis in these immunized animals appeared not to be possible anymore. Subsequent experiments revealed that the same protection against adjuvant arthritis induction was obtained by immunizing the animals with only a conserved sequence (peptide) of mycobacterial HSP60 (90). On the basis of these latter experiments, it was concluded that the conserved peptide induced $\mathrm{T}$ cells that were cross-reactive with self (mammalian) HSP upregulated at the site of inflammation. In various additional studies, the regulatory nature of these cross-reactive $\mathrm{T}$ cells was recognized, since they were producing regulatory cytokines such as IL-10.

More recent studies have shown the HSP mediated induction of $\mathrm{T}$ cells with regulatory potential, which showed the actual phenotypic characteristics of the currently known Tregs (91). This was among others the case for an HSP70 derived conserved mycobacterial peptide called B29. When BALB/c mice were immunized with B29, responding $\mathrm{T}$ cells were collected on the basis of CD25 expression and transferred into naïve syngeneic recipient mice. Subsequently, these T cells were found to inhibit 
disease activity after induction of arthritis and to persist in various organs, including the joints, for more than 50 days. When during this time period, the presence of these cells was interrupted by infusion of a Treg depleting antibody, disease returned, which showed the actual disease suppressive activity of these HSP70-specific Tregs. When B29-specific T cells were selected on the basis of LAG-3 expression, it sufficed to transfer only 4,000 of these T cells to fully inhibit arthritis. Several explanations are possible for the capacity of conserved microbial HSP peptides to induce Tregs. An obvious explanation can be found in the contact of the immune system with microbiota in the gut. It is known that APCs lining the gut mucosa ingest bacteria from the microbiota. This causes transport to mesenteric lymph nodes, where the derivative microbial antigens are presented to $\mathrm{T}$ cells, a phenomenon that must contribute to mucosal tolerance. Since ingestion of bacteria will lead to a stress response, both in bacteria and in the APC of the host, MHC molecules will be loaded with HSP fragments in this process. By these mechanisms, both microbial and the self-cross-reactive $\mathrm{T}$ cells will be activated. And since such events happen in the environment of the tolerance promoting mucosa, induction of peripheral Tregs seems a direct and physiological consequence. Given the evolutionary conservation of the HSP molecules present in the complete kingdom of prokaryotes, it seems unavoidable that through the repeated contacts with bacteria, the immune system develops a focus on the conserved parts of the molecules. And by this same focus on the shared sequences between bacterial and mammalian HSPs, Tregs induced by bacterial HSP may easily cross-respond to self-HSP (over-)expressed in the inflamed tissues. Herewith the regulation, which is of a bystander nature, will be targeted toward the sites of inflammation.

\section{Endogenous HSP-Loaded MHC Molecules}

Apart from the possibility that mucosal tolerance creates a repertoire of HSP-specific Treg, there is also reason to think that HSPs are a default antigen for Tregs in the context of healthy tolerogenic APCs in the absence of co-stimulation activating microorganisms. In various studies, HSP70 has been found to belong to the most frequent cytosolic/nuclear MHC class II natural ligand sources (92). In other words, MHC elution studies have revealed that sequences of HSP70 family members are relatively often present in the proteome obtained from the antigen-binding clefts of human and mouse MHC-II molecules. And especially in the case of cell stress, such as the stress caused by inflammatory mediators, HSP70 fragments have been seen to become preferentially uploaded into MHC-II molecules [reviewed in Ref. (87)]. Dengjel et al. (93) have analyzed the sequences eluted from human B cell-derived HLA-DR4 molecules under amino-acid deprivation as the cell-stress factor. It was shown that under such conditions chaperone-mediated autophagy became operative, which led to involvement of HSP70, which is one of the molecular participants in the process of chaperone mediated autophagy. In general terms, it was seen that under stress, the presentation of peptides from intracellular and lysosomal source proteins was strongly increased on MHC-II in contrast to peptides from membrane and secreted proteins. For these reasons, it was concluded that their study illustrated a profound influence of autophagy on the class II peptide repertoire and suggested that this finding had implications for the regulation of CD4(+) T cell-mediated processes. Interestingly, also the mammalian homologs of our earlier defined HSP70-derived B29 peptide were eluted from this HLA-DR4 molecule (HLA DRB $1^{\star} 0401$ ). Knowing this, it seems reasonable to think that HSPs and HSP70 family members in particular are frequently seen by Tregs in the context of MHC-II molecules. In this manner, they could well serve as a default antigen for Tregs, especially when presented by tolerogenic APC.

Given the stress-inducible nature of various HSP70 family members, we have attempted to raise the abundance of HSP70 fragments in MHC-II molecules of APCs by administering a socalled HSP co-inducing compound $(94,95)$. And indeed, in the experimental model of proteoglycan-induced arthritis (PGIA) in mice, we have seen such an intervention with an HSP co-inducer to lead to a T cell-mediated resistance against arthritis. The experiments were carried out with carvacrol, an essential oil obtained from Oregano plants. Initial studies in vitro had indicated that incubation of cells before further exposure to classical stressors, such as raised temperature or arsenite, caused a raised expression of endogenous HSP70. When given orally, carvacrol was found to lead to a raised expression of HSP70 family members in the Peyer's patches, the lymphoid organs of the gut. In addition, when analyzing the $\mathrm{T}$ cell responses to HSP70, it was found that oral carvacrol had raised the frequency of HSP70-specific $\mathrm{T}$ cells and that such cells showed to an enhanced degree the $\mathrm{CD}^{+}{ }^{+} \mathrm{CD} 25^{+} \mathrm{Foxp}^{+}$phenotype of Tregs. Transfer of these cells into naïve recipients inhibited subsequently induced PGIA. Thus, the experiments with carvacrol have indicated that for the purpose of generating therapeutic tolerance, the co-induction of HSPs, even by dietary measures, may be a possible and attractive strategy.

\section{How to Induce HSP-Based Therapeutic Tolerance in T Cell-Mediated Autoimmune Diseases}

Effective interventions in animal models are usually based on disease inhibition by administering therapeutics before disease induction. In other words, effective interventions are mostly preventive and not therapeutic. Successful therapeutic interventions, when overt disease has been established, are notoriously difficult to reach. The reason for this is that established inflammation is known to cause a relative resistance to therapy, among others by a supposed resistance of effector cells to the regulation by Tregs (96). For these reasons, it seems essential for therapeutic tolerance to become an effective intervention, to treat chronic inflammatory diseases in an early phase of the disease.

Initial clinical studies in patients with autoimmune diseases with a recent diagnosis using peptides derived from HSP have shown that the treatment is safe and also the possibility to skew the pro-inflammatory profile of pathogenic T-cell clones has been noted [reviewed in Ref. (97-99)]. For example, dnaJP1 is a 15 mer peptide, derived from bacterial HSP 40 , that shares homology with the "shared epitope" sequence present in some HLA-class II molecules associated with RA, which confers susceptibility to develop the disease. The peptide was identified 
as a pro-inflammatory $\mathrm{T}$ cell epitope in patients with active RA $(100,101)$, and authors hypothesized that it could be involved in the amplification of the inflammation due to the loss of regulatory mechanisms. In the double-blind, placebo-controlled phase II trial, dnaJP1 was administrated to active RA patients ( $<5$ years of diagnosis) with the aim of inducing mucosal tolerance to this pro-inflammatory epitope. The treatment consisted in the administration of $25 \mathrm{mg}$ of the peptide by oral route daily for 6 months. A decreased percentage of $\mathrm{CD}^{+} \mathrm{T}$ cells producing TNF- $\alpha$ in response to restimulation in vitro with dnaJP1 was observed in patients treated with the peptide but not with placebo. A trend toward increased levels of IL-10 was seen only in clinical responders. The expression of certain molecules associated with the downregulation of the immune response before the therapy was found necessary for successfully tolerization using this peptide. Finally, authors reported significant differences between treatment groups on day 140 for both American College of Rheumatology (ACR)20 and ACR50 responses (102).

More recently, a randomized placebo-controlled double-blind phase I/IIA trial was performed in patients with unresponsive active RA using binding immunoglobulin protein ( $\mathrm{BiP})$. $\mathrm{BiP}$ is an endoplasmic reticulum resident chaperone and stress protein with strong tolerogenic effects in the collagen-induced arthritis model (103). A single i.v. infusion of $\operatorname{BiP}(1,5$, or $15 \mathrm{mg})$ was well tolerated. The efficacy in this study was confounded by a high clinical response in the placebo group. However, at the end of the follow up period (12 weeks), remission was only achieved by some patients receiving 5 and $15 \mathrm{mg}$ of BiP. Decreased C-reactive protein levels, VEGF, and IL-8 were decreased in patients receiving $\mathrm{BiP}$ compared with placebo at that time point (104). Finally, it was concluded that a large study is required to find the optimum dose and frequency of BiP administration.

Antigen-specific tolerance using HSP-derived peptides has also been explored in T1D. DiaPep277 is a 24-amino-acid peptide derived from the 437-460 sequence of HSP60. The treatment of newly diagnosed diabetic patients with DiaPep277 was well tolerated. In some patients, the treatment may delay the loss of the C-peptide production thereby decreasing the demand for exogenous insulin when compared with placebo groups in phase I and II clinical trials (105). The study of the T-cell populations of patients treated with DiaPep277 but not with placebo showed a shift toward a Th2 phenotype characterized by reduced levels of IFN- $\gamma$ and increased expression of IL-4, IL-10, and IL-13 (106).

In general, immunological effects often correlate with a trend to clinical efficacy compared with placebo groups. However, the

\section{REFERENCES}

1. Vyse T, Todd J. Genetic analysis of autoimmune disease. Cell (1996) 85:311-8. doi:10.1016/S0092-8674(00)81110-1

2. Cho J, Gregersen PK. Genomics and the multifactorial nature of human autoimmune disease. N Engl J Med (2011) 365:1612-23. doi:10.1056/NEJMra1100030

3. Parkes M, Cortes A, van Heel DA, Brown MA. Genetic insights into common pathways and complex relationships among immune-mediated diseases. Nat Rev Genet (2013) 14:661-73. doi:10.1038/nrg3502

4. Sakaguchi S, Wing K, Onishi Y, Prieto-Martin P, Yamaguchi T. Regulatory $\mathrm{T}$ cells: how do they suppress immune responses? Int Immunol (2009) 21(10):1105-11. doi:10.1093/intimm/dxp095 clinical efficacy has been less than expected. Therefore, it may turn out necessary to combine various strategies. For example, anti-TNF- $\alpha$ drugs may be combined with HSP peptide-based vaccination to have a synergic effect of inhibition of inflammation in combination with a Treg inducing strategy. A recently probed intervention was utilizing autologous tolerogenic dendritic cells (DCs) loaded with (autologous) synovial fluids in patients with progressive forms of RA (107). This first phase clinical trial showed the safety and the attainability of the approach. Although in some patients also a beneficial clinical effect was noted, it now seems needed to repeat such an intervention in patients with less advanced forms of the disease. Since it will be less practical to obtain synovial fluids from such patients, an attractive alternative possibility will be the use of HSP70 peptide B29. Besides the fact that B29 has shown a capacity to induce HSP70-specific Tregs, an additional advantage of using a well-defined antigen, such as B29, is that this will provide an opportunity to monitor the effect of the intervention precisely at the level of peptide-specific T cells. A clinical trial exploring the effect of B29 in combination with tolerogenic DCs in patients with RA is under development.

Although clearly in its infancy, therapeutic tolerance is expected to become a reality. In the case of RA, therapeutic progress has been significant until now. From the first pain killers, such as aspirin that was already available in the end of the nineteenth century, gold preparations since the 30 s of the previous century, prednisone since World War II and biologics more recently, a very significant progress was made. The typical anatomical joint aberrations as they were seen frequently in RA patients are fully avoidable these days. Nonetheless, none of these interventions leads to cure. When therapy is halted, disease returns. Knowing this, the real challenge for the coming years will be the development of interventions that lead to a permanent remission based on regained self-tolerance. Given their supposed physiological role as targets for $\mathrm{T}$ cell regulation, HSPs may provide us possibly with the means to achieve true therapeutic tolerance.

\section{AUTHOR CONTRIBUTIONS}

$\mathrm{AB}, \mathrm{QL}$, and WE did the writing. FB, AS, and VR were involved with the design of the paper.

\section{FUNDING}

The authors thank the Dutch Reumafonds for continued support. QL is supported by a grant from the Chinese government (CSC).

5. Fontenot JD, Gavin MA, Rudensky AY. FoxP3 programs the development and function of CD4(+)CD25(+) regulatory T cells. Nat Immunol (2003) 4(4):330-6. doi:10.1038/ni904

6. Sakaguchi S. Naturally arising $\mathrm{CD}^{+}$regulatory $\mathrm{T}$ cells for immunologic selftolerance and negative control of immune responses. Ann Rev Immunol (2004) 22:531. doi:10.1146/annurev.immunol.21.120601.141122

7. Fontenot JD, Rudensky AY. A well adapted regulatory contrivance: regulatory $\mathrm{T}$ cell development and the forkhead family transcription factor FoxP3. Nat Immunol (2005) 6:331. doi:10.1038/ni1179

8. Strioga M, Pasukoniene V, Characiejus D. CD8 ${ }^{+} \mathrm{CD} 28^{-}$and $\mathrm{CD} 8^{+} \mathrm{CD} 57^{+}$ $\mathrm{T}$ cells and their role in health and disease. Immunology (2011) 134(1):17-32. doi:10.1111/j.1365-2567.2011.03470.x 
9. Suciu-Foca N, Manavalan JS, Scotto L, Kim-Schulze S, Galluzzo S, Naiyer AJ, et al. Molecular characterization of allospecific T suppressor and tolerogenic dendritic cells: review. Int Immunopharmacol (2005) 5:7-11. doi:10.1016/j. intimp.2004.09.003

10. Vlad G, Cortesini R, Suciu-Foca N. License to heal: bidirectional interaction of antigen-specific regulatory T cells and tolerogenic APC. J Immunol (2005) 174:5907-14. doi:10.4049/jimmunol.174.10.5907

11. Vlad G, King J, Chang CC, Liu Z, Friedman RA, Torkamani AA, et al. Gene profile analysis of $\mathrm{CD}^{+}$ILT3-Fc induced T suppressor cells. Hum Immunol (2011) 72:107-14. doi:10.1016/j.humimm.2010.10.012

12. Buckner JH. Mechanisms of impaired regulation by CD4+CD25+FoxP3+ regulatory T cells in human autoimmune diseases. Nat Rev Immunol (2010) 10:849-59. doi:10.1038/nri2889

13. Dinesh R, Skaggs B, La Cava A, Hahn BH, Singh R. CD8+Tregs in lupus, autoimmunity, and beyond. Autoimmun Rev (2010) 9(8):560-8. doi:10.1016/j. autrev.2010.03.006

14. Fessler J, Felber A, Duftner C, Dejaco C. Therapeutic potential of regulatory $\mathrm{T}$ cells in autoimmune disorders. BioDrugs (2013) 27:281-91. doi:10.1007/ s40259-013-0026-5

15. Zaccone P, Cooke A. Harnessing CD8+ regulatory T cells: therapy for type 1 diabetes? Immunity (2010) 32(4):504-6. doi:10.1016/j.immuni.2010.04.009

16. Bluestone JA. Is CTLA-4 a master switch for peripheral T cell tolerance? J Immunol (1997) 158:1989-93.

17. Tivol E, Borriello F, Schweitzer A, Lynch W, Bluestone J, Sharpe A. Loss of CTLA-4 leads to massive lymphoproliferation and fatal multiorgan tissue destruction, revealing a critical negative regulatory role of CTLA-4. Immunity (1995) 3(5):541-7. doi:10.1016/1074-7613(95)90125-6

18. Kristiansen O, Larsen Z, Pociot F. CTLA-4 in autoimmune diseases a general susceptibility gene to autoimmunity? Genes Immun (2000) 1:170-84. doi:10.1038/sj.gene.6363655

19. Aggarwal BB. Signalling pathways of the TNF superfamily: a double-edged sword. Nat Rev Immunol (2003) 3:745-56. doi:10.1038/nril184

20. Bohana-Kashtan O, Civin CI. Fas ligand as a tool for immunosuppression and generation of immune tolerance. Stem Cells (2004) 22:908-24. doi:10.1634/stemcells.22-6-908

21. Zhang X, Brunner T, Carter L, Dutton RW, Rogers P, Bradley L, et al. Unequal death in T helper cell (Th)1 and Th2 effectors: Th1, but not Th2, effectors undergo rapid Fas/FasL-mediated apoptosis. J Exp Med (1997) 185:1837-49. doi:10.1084/jem.185.10.1837

22. Varadhachary AS, Perdow SN, Hu C, Ramanarayanan M, Salgame P. Differential ability of $\mathrm{T}$ cell subsets to undergo activation-induced cell death. Proc Natl Acad Sci U S A (1997) 94:5778-83. doi:10.1073/pnas. 94.11.5778

23. Pandiyan P, Zheng L, Ishihara S, Reed J, Lenardo MJ. CD4+CD25+Foxp3+ regulatory $\mathrm{T}$ cells induce cytokine deprivation-mediated apoptosis of effector CD4+ T cells. Nat Immunol (2007) 8(12):1353-62. doi:10.1038/ni1536

24. Cao X, Cai SF, Fehniger TA, Song J, Collins LI, Piwnica-Worms DR, et al. Granzyme B and perforin are important for regulatory $\mathrm{T}$ cell-mediated suppression of tumor clearance. Immunity (2007) 27(4):635-46. doi:10.1016/j. immuni.2007.08.014

25. Gallucci S, Lolkema M, Matzinger P. Natural adjuvants: endogenous activators of dendritic cells. Nat Med (1999) 5:1249-55. doi:10.1038/15200

26. Morelli AE, Thomson AW. Tolerogenic dendritic cells and the quest for transplant tolerance. Nat Rev Immunol (2007) 7:610-21. doi:10.1038/nri2132

27. Stoop JN, Harry R, von Delwig A, Isaacs J, Robinson J, Hilkens C. Therapeutic effect of tolerogenic dendritic cells in established collagen-induced arthritis is associated with a reduction in Th17 responses. Arthritis Rheum (2010) 62:3656-65. doi:10.1002/art.27756

28. Thomson AW, Robbins PD. Tolerogenic dendritic cells for autoimmune disease and transplantation. Ann Rheum Dis (2008) 67(3):iii90-6. doi:10.1136/ ard.2008.099176

29. Oderup C, Cederbom L, Makowska A, Cilio CM, Ivars F. Cytotoxic T lymphocyte antigen-4-dependent down-modulation of costimulatory molecules on dendritic cells in CD4+ CD25+regulatory T-cell-mediated suppression. Immunology (2006) 118:240-9. doi:10.1111/j.1365-2567.2006.02362.x

30. Grohmann U, Orobona C, Fallarino F, Vacca C, Calcinaro F, Falorni A, et al. CTLA-4-Ig regulates tryptophan catabolism in vivo. Nat Immunol (2002) 3:1097-101. doi:10.1038/ni846
31. Fallarino F, Grohmann U, Hwang KW, Orabona C, Vacca C, Bianchi R, et al. Modulation of tryptophan catabolism by regulatory T cells. Nat Immunol (2003) 4:1206-12. doi:10.1038/ni1003

32. Liang B, Workman C, Lee J, Chew C, Dale BM, Colonna L, et al. Regulatory $\mathrm{T}$ cells inhibit dendritic cells by lymphocyte activation gene- 3 engagement of MHC class II. J Immunol (2008) 180:5916-26. doi:10.4049/jimmunol. 180.9.5916

33. McInnes IB, Schett G. The pathogenesis of rheumatoid arthritis. N Engl J Med (2011) 365:2205-19. doi:10.1056/NEJMra1004965

34. Gregersen PK, Silver J, Winchester RJ. The shared epitope hypothesis. An approach to understanding the molecular genetics of susceptibility to rheumatoid arthritis. Arthritis Rheum (1987) 30:1205-13. doi:10.1002/art. 1780301102

35. Holoshitz J. The rheumatoid arthritis HLA-DRB1 shared epitope. Curr Opin Rheumatol (2010) 22(3):293-8. doi:10.1097/BOR.0b013e328336ba63

36. Cope A, Schulze-Koops H, Aringer M. The central role of T cells in rheumatoid arthritis. Clin Exp Rheumatol (2007) 25(5 Suppl 46):S4-11.

37. Toh ML, Miossec P. The role of T cells in rheumatoid arthritis: new subsets and new targets. Curr Opin Rheumatol (2007) 19:284-8. doi:10.1097/BOR. 0b013e32805e $87 \mathrm{e} 0$

38. Nistala K, Wedderburn LR. Th17 and regulatory T cells: rebalancing pro- and anti-inflammatory forces in autoimmune arthritis. Rheumatology (Oxford) (2009) 48:602-6. doi:10.1093/rheumatology/kep028

39. Wang W, Shao S, Jiao Z, Guo M, Xu H, Wang S. The Th17/Treg imbalance and cytokine environment in peripheral blood of patients with rheumatoid arthritis. Rheumatol Int (2012) 32:887-93. doi:10.1007/s00296-010-1710-0

40. Davignon J, Hayder M, Baron M, Boyer J, Constantin A, Apparailly F, et al. Targeting monocytes/macrophages in the treatment of rheumatoid arthritis. Rheumatology (Oxford) (2013) 52(4):590-8. doi:10.1093/rheumatology/kes304

41. Albani S, Koffeman EC, Prakken B. Induction of immune tolerance in the treatment of rheumatoid arthritis. Nat Rev Rheumatol (2011) 7(5):272-81. doi:10.1038/nrrheum.2011.36

42. Ehrenstein MR, Evans JG, Singh A, Moore S, Warnes G, Isenberg DA, et al. Compromised function of regulatory $\mathrm{T}$ cells in rheumatoid arthritis and reversal by anti-TNF therapy. J Exp Med (2004) 200(3):277-85. doi:10.1084/ jem. 20040165

43. Nadkarni S, Mauri C, Ehrenstein MR. Anti-TNF- $\alpha$ therapy induces a distinct regulatory $\mathrm{T}$ cell population in patients with rheumatoid arthritis via TGF- $\beta$. J Exp Med (2007) 204(1):33-9. doi:10.1084/jem.20061531

44. Rubbert-Roth A. Assessing the safety of biologic agents in patients with rheumatoid arthritis. Rheumatology (2012) 51:v38-47. doi:10.1093/ rheumatology/kes114

45. Maahs DM, West NA, Lawrence JM, Mayer-Davis EJ. Chapter 1: epidemiology of type 1 diabetes. Endocrinol Metab Clin North Am (2010) 39(3):481-97. doi:10.1016/j.ecl.2010.05.011

46. Patterson C, Guariguata L, Dahlquist G, Soltész G, Ogle G, Silink M. Diabetes in the young - a global view and worldwide estimates of numbers of children with type 1 diabetes. Diabetes Res Clin Pract (2014) 103(2):161-75. doi:10.1016/j.diabres.2013.11.005

47. Patterson C, Dahlquist G, Gyürüs E, Green A, Soltész G; EURODIAB Study Group. Incidence trends for childhood type 1 diabetes in Europe during 19892003 and predicted new cases 2005-20: a multicentre prospective registration study. Lancet (2009) 373:2027-33. doi:10.1016/S0140-6736(09)60568-7

48. Erlich H, Valdes AM, Noble J, Carlson JA, Varney M, Concannon P, et al. HLA DR-DQ haplotypes and genotypes and type 1 diabetes risk: analysis of the type 1 diabetes genetics consortium families. Diabetes (2008) 57:1084-92. doi:10.2337/db07-1331

49. Arif S, Tree TI, Astill T, Tremble JM, Bishop A, Dayan C, et al. Autoreactive $\mathrm{T}$ cell responses show proinflammatory polarization in diabetes but a regulatory phenotype in health. JClin Invest (2004) 113:451-63. doi:10.1172/ JCI19585

50. Lindley S, Dayan CM, Bishop A, Roep BO, Peakman M, Tree T. Defective suppressor function in $\mathrm{CD} 4(+) \mathrm{CD} 25(+)$ T-cells from patients with type 1 diabetes. Diabetes (2005) 54:92-9. doi:10.2337/diabetes.54.1.92

51. Haseda F, Imagawa A, Murase-Mishiba Y, Terasaki J, Hanafusa T. CD4(+) CD45RA(-) FoxP3high activated regulatory $\mathrm{T}$ cells are functionally impaired and related to residual insulin-secreting capacity in patients with type 1 diabetes. Clin Exp Immunol (2013) 173:207-16. doi:10.1111/cei.12116 
52. van Belle TL, Coppieters KT, von Herrath MG. Type 1 diabetes etiology, immunology, and therapeutic strategies. Physiol Rev (2011) 91:79-118. doi:10.1152/physrev.00003.2010

53. Greenbaum C, Atkinson M. Persistence is the twin sister of excellence: an important lesson for attempts to prevent and reverse type 1 diabetes. Diabetes (2011) 60:693-4. doi:10.2337/db10-1810

54. von Herrath M, Peakman M, Roep B. Progress in immune-based therapies for type 1 diabetes. Clin Exp Immunol (2013) 172:186-202. doi:10.1111/cei.12085

55. Sherry N, Hagopian W, Ludvigsson J, Jain S, Wahlen J, Ferry RJ Jr, et al. Teplizumab for treatment of type 1 diabetes (Protege study): 1-year results from a randomised, placebo-controlled trial. Lancet (2011) 378:487-97. doi:10.1016/S0140-6736(11)60931-8

56. Bach JF. Anti-CD3 antibodies for type 1 diabetes: beyond expectations. Lancet (2011) 378:459-60. doi:10.1016/S0140-6736(11)60980-X

57. Palmares J, Castro-Correia J, Coutinho M, Mendes A, Delgado L. HLA and idiopathic uveitis. Ocul Immunol Inflamm (1993) 1(1-2):179-85. doi:10.3109/ 09273949309086557

58. LeHoang P, Ozdemir N, Benhamou A, Tabary T, Edelson C, Betuel H, et al. HLA-A29. 2 subtype associated with birdshot retinochoroidopathy. Am J Ophthalmol (1992) 113(1):33-5. doi:10.1016/S0002-9394(14)75749-6

59. Davis J, Mittal K, Freidlin V, Mellow SR, Optican D, Palestine A, et al. HLA associations and ancestry in Vogt-Koyanagi-Harada disease and sympathetic ophthalmia. Ophthalmology (1990) 97(9):1137-42. doi:10.1016/ S0161-6420(90)32446-6

60. Brewerton DA, Caffrey M, Nicholls A, Walters D, James D. Acute anterior uveitis and HLA-27. Lancet (1973) 302:994-6. doi:10.1016/S0140-6736(73)91090-8

61. Khan M. Polymorphism of HLA-B27: 105 subtypes currently known. Curr Rheumatol Rep (2013) 15(10):362. doi:10.1007/s11926-013-0362-y

62. Chang J, McCluskey P, Wakefield D. Acute anterior uveitis and HLA-B27. Surv Ophthalmol (2005) 50(4):364-88. doi:10.1016/j.survophthal.2005.04.003

63. Li H, Li Q, Ji C, Gu J. Ankylosing spondylitis patients with HLA-B* 2704 have more uveitis than patients with HLA-B* 2705 in a North Chinese population. Ocul Immunol Inflamm (2016):1-5. doi:10.1080/09273948.2016.1188967

64. Konno Y, Numaga J, Tsuchiya N, Ogawa A, Islam S, Mochizuki M, et al. HLA-B27 subtypes and HLA class II alleles in Japanese patient with anterior uveitis. Invest Ophthalmol Vis Sci (1999) 40(8):1838-44.

65. Linssen A, Meenken C. Outcomes of HLA-B27-positive and HLA-B27negative acute anterior uveitis. Am JOphthalmol (1995) 120(3):351-61. doi:10.1016/S0002-9394(14)72165-8

66. Khan M, Kushner I, Braun W. Comparison of clinical features in HLA-B27 positive and negative patients with ankylosing spondylitis. Arthritis Rheum (1977) 20(4):909-12. doi:10.1002/art.1780200401

67. Bodaghi B, Touitou V, Fardeau C, Chapelon C, LeHoang P. Ocular sarcoidosis. La Presse Médicale (2012) 41(6):e349-54. doi:10.1016/j.lpm.2012.04.004

68. Bloch-Michel E, Frau E. Birdshot retinochoroidopathy and HLA-A29+ and HLA-A29-idiopathic retinal vasculitis: comparative study of 56 cases. Can J Ophthalmol (1991) 26(7):361-6.

69. Holdsworth R, Hurley CK, Marsh SG, Lau M, Noreen HJ, Kempenich JH, et al. The HLA dictionary 2008: a summary of HLA-A,-B,-C,-DRB1/3/4/5, and-DQB1 alleles and their association with serologically defined HLAA,-B,-C,-DR, and-DQ antigens. Tissue Antigens (2009) 73(2):95-170. doi:10.1111/j.1399-0039.2008.01183.x

70. Cao K, Hollenbach J, Shi X, Shi W, Chopek M, Fernández-Viña M. Analysis of the frequencies of HLA-A, B, and C alleles and haplotypes in the five major ethnic groups of the United States reveals high levels of diversity in these loci and contrasting distribution patterns in these populations. Hum Immunol (2001) 62(9):1009-30. doi:10.1016/S0198-8859(01)00298-1

71. Kaya T. Genetics of Behçet's disease. Pathol Res Int (2012) 2012:912589. doi:10.1155/2012/912589

72. Arber N, Klein T, Meiner Z, Pras E, Weinberger A. Close association of HLAB51 and B52 in Israeli patients with Behçet's syndrome. Annals Rheum Dis (1991) 50(6):351-3. doi:10.1136/ard.50.6.351

73. Zhang L, Wan F, Song J, Tang K, Zheng F, Guo J, et al. Imbalance between Th17 cells and regulatory $\mathrm{T}$ cells during monophasic experimental autoimmune uveitis. Inflammation (2016) 39(1):113-22. doi:10.1007/s10753-015-0229-7

74. Zhuang Z, Wang Y, Zhu G, Gu Y, Mao L, Hong M, et al. Imbalance of Th17/Treg cells in pathogenesis of patients with human leukocyte antigen B27 associated acute anterior uveitis. Sci Rep (2017) 7:40414. doi:10.1038/ srep40414
75. Takeda A, Sonoda K, Ishibashi T. Regulation of Th1 and Th17 cell differentiation in uveitis. Inflamm Regen (2013) 33(5):261-8. doi:10.2492/ inflammregen.33.261

76. Pockley AG, Muthana M, Calderwod SK. The dual immunoregulatory roles of stress proteins. Trends Biochem Sci (2008) 33(2):71-9. doi:10.1016/j. tibs.2007.10.005

77. Asea A, Kraeft SK, Kurt-Jones EA, Stevenson MA, Chen LB, Finberg RW, et al. HSP70 stimulates cytokine production through a CD14-dependant pathway, demonstrating its dual role as a chaperone and cytokine. Nat Med (2000) 6:435-42. doi:10.1038/74697

78. van Eden W, Spiering R, Broere F, van der Zee R. A case of mistaken identity: HSPs are no DAMPs but DAMPERs. Cell Stress and Chaperones (2012) 17:281-92. doi:10.1007/s12192-011-0311-5

79. Bausinger H, Lipsker D, Ziylan U, Manié S, Briand JP, Cazenave JP, et al. Endotoxin-free heat-shock protein 70 fails to induce APC activation. Eur J Immunol (2002) 32:3708-13. doi:10.1002/1521-4141(200212)32:12<3708:: AID-IMMU3708 $>3.0$. CO;2-C

80. Bendz H, Marincek BC, Momburg F, Ellwart JW, Issels RD, Nelson PJ, et al. Calcium signaling in dendritic cells by human or mycobacterial Hsp70 is caused by contamination and is not required for Hsp70-mediated enhancement of cross-presentation. J Biol Chem (2008) 283:26477-83. doi:10.1074/jbc. M803310200

81. Zanin-Zhorov A, Nussbaum G, Franitza S, Cohen IR, Lider O. T cells respond to heat shock protein 60 via TLR2: activation of adhesion and inhibition of chemokine receptors. FASEB J (2003) 17:1567-9. doi:10.1096/ff.02-1139fje

82. Asea A, Rehli M, Kabing E, Boch JA, Bare O, Auron PE. Novel signal transduction pathway utilized by extracellular HSP70: role of toll-like receptor (TLR) 2 and TLR4. J Biol Chem (2002) 277(17):15028-34. doi:10.1074/jbc. M200497200

83. Quintana F, Cohen I. The HSP60 immune system network. Trends in Immunol (2011) 32(2):89-95. doi:10.1016/j.it.2010.11.001

84. Munk M, Schoel B, Modrow S, Karr R, Young R, Kaufmann S. T lymphocytes from healthy individuals with specificity to self-epitopes shared by the mycobacterial and human 65-kilodalton heat shock protein. J Immunol (1989) 143:2844-9.

85. Pockley A, Bulmer J, Hanks B, Wright B. Identification of human heat shock protein 60 (Hsp60) and anti-Hsp60 antibodies in the peripheral circulation of normal individuals. Cell Stress Chaperones (1999) 4:29-35. doi:10.1379/ 1466-1268(1999)004<0029:IOHHSP > 2.3.CO;2

86. van Eden W, van der Zee R, Paul A, Prakken BJ, Wendling U, Anderton SM, et al. Do heat shock proteins control the balance of T-cell regulation in inflammatory diseases? Immunol Today (1998) 19:303-7. doi:10.1016/S01675699(98)01283-3

87. van Eden W, van Herwijnen M, Wagenaar J, van Kooten P, Broere F, van der Zee R. Stress proteins are used by the immune system for cognate interactions with anti-inflammatory regulatory T cells. FEBS Lett (2013) 587:1951-8. doi:10.1016/j.febslet.2013.05.024

88. Wieten L, Broere F, van der Zee R, Koerkamp EK, Wagenaar J, van Eden W. Cell stress induced HSP are targets of regulatory T cells: a role for HSP inducing compounds as anti-inflammatory immunomodulators? FEBS Lett (2007) 581:3716-22. doi:10.1016/j.febslet.2007.04.082

89. van Eden W, Tholet JE, van der Zee R, Noordzij A, van Embden J, Hensen E, et al. Cloning of the mycobacterial epitope recognized by $\mathrm{T}$ lymphocytes in adjuvant arthritis. Nature (1988) 331:171-3. doi:10.1038/331171a0

90. Anderton S, van der Zee R, Prakken B, Noordzij A, van Eden W. Activation of $\mathrm{T}$ cells recognizing self $60-\mathrm{kD}$ heat shock protein can protect against experimental arthritis. J Exp Med (1995) 181(3):943-52. doi:10.1084/jem.181. 3.943

91. van Herwijnen M, Wieten L, van der Zee R, van Kooten P, Wagenaar-Hilbers J, Hoek A, et al. Regulatory T cells that recognize a ubiquitous stress-inducible self-antigen are long-lived suppressors of autoimmune arthritis. Proc Natl Acad Sci U S A (2012) 109(35):14134-9. doi:10.1073/pnas.1206803109

92. Paludan C, Schmid D, Landthaler M, Vockerodt M, Kube D, Tuschl T, et al. Endogenous MHC class II processing of a viral nuclear antigen after autophagy. Science (2005) 307(5709):593-6. doi:10.1126/science.1104904

93. Dengjel J, Schoor O, Fischer R, Reich M, Kraus M, Müller M, et al. Autophagy promotes MHC class II presentation of peptides from intracellular source proteins. Proc Natl Acad Sci U S A (2005) 102(22):7922-7. doi:10.1073/ pnas. 0501190102 
94. Wieten L, van der Zee R, Spiering R, Wagenaar-Hilbers J, van Kooten P, Broere F, et al. A novel heat-shock protein coinducer boosts stress protein Hsp70 to activate $\mathrm{T}$ cell regulation of inflammation in autoimmune arthritis. Arthritis Rheum (2010) 62(4):1026-35. doi:10.1002/art.27344

95. Wieten L, van der Zee R, Goedemans R, Sijtsma J, Serafini M, Lubsen NH, et al. Hsp70 expression and induction as a readout for detection of immune modulatory components in food. Cell Stress Chaperones (2010) 15(1):25-37. doi:10.1007/s12192-009-0119-8

96. van Loosdregt J, Fleskens V, Tiemessen M, Mokry M, van Boxtel R, Meerding J, et al. Canonical Wnt signaling negatively modulates regulatory $\mathrm{T}$ cell function. Immunity (2013) 39(2):298-310. doi:10.1016/j.immuni.2013.07.019

97. Spierings J, van Eden W. Heat shock proteins and their immunomodulatory role in inflammatory arthritis. Rheumatology (2017) 56:198-208. doi:10.1093/rheumatology/kew266

98. Barbera A, Broere F, van Eden W. Heat shock proteins as target for the induction of antigen-specific tolerance in rheumatoid arthritis and other chronic inflammatory diseases. J Autoimmune Dis Rheumatol (2015) 3(2): 41-52. doi:10.12970/2310-9874.2015.03.02.3

99. Zonneveld-Huijssoon E, Albani S, Prakken BJ, van Wijk F. Heat shock protein bystander antigens for peptide immunotherapy in autoimmune disease. Clin Exp Immunol (2013) 171(1):20-9. doi:10.1111/j.1365-2249.2012.04627.x

100. Albani S, Keystone EC, Nelson JL, Ollier WE, La Cava A, Montemayor AC, et al. Positive selection in autoimmunity: abnormal immune responses to a bacterial dnaJ antigenic determinant in patients with early rheumatoid arthritis. Nat Med (1995) 1:448-52. doi:10.1038/nm0595-448

101. Albani S, Tuckwell J, Carson D, Roudier J. The susceptibility sequence to rheumatoid arthritis is a cross-reactive B cell epitope shared by the Escherichia coli heat shock protein dnaJ and the histocompatibility leucocyte antigen DRB10401 molecule. J Clin Invest (1992) 89:327-31. doi:10.1172/JCI115580

102. Koffeman EC, Genovese M, Amox D, Keogh E, Santana E, Matteson EL, et al. Epitope-specific immunotherapy of rheumatoid arthritis: clinical responsiveness occurs with immune deviation and relies on the expression of a cluster of molecules associated with T cell tolerance in a double-blind, placebo-controlled, pilot phase II trial. Arthritis Rheum (2009) 60(11): 3207-16. doi:10.1002/art.24916

103. Shields AM, Panayi G, Corrigall V. A new-age for biologic therapies: longterm drug-free therapy with BiP? Front Immunol (2012) 3:17. doi:10.3389/ fimmu.2012.00017

104. Kirkham B, Chaabo K, Hall C, Garrood T, Mant T, Allen E, et al. Safety and patient response as indicated by biomarker changes to binding immunoglobulin protein in the phase I/IIA RAGULA clinical trial in rheumatoid arthritis. Rheumatology (Oxford) (2016) 55(11):1993-2000. doi:10.1093/ rheumatology/kew287

105. Schloot N, Cohen I. DiaPep $277^{\oplus}$ and immune intervention for treatment of type 1 diabetes. Clin Immunol (2013) 149:307-16. doi:10.1016/j.clim. 2013.09.001

106. Raz I, Elias D, Avron A, Tamir M, Metzger M, Cohen IR. $\beta$-cell function in new-onset type 1 diabetes and immunomodulation with a heat shock protein peptide (DiaPep277): a randomised, double-blind, phase II trial. Lancet (2001) 358(9295):1749-53. doi:10.1016/S0140-6736(01)06801-5

107. Bell G, Anderson A, Diboll J, Reece R, Eltherington O, Harry R, et al. Autologous tolerogenic dendritic cells for rheumatoid and inflammatory arthritis. Ann Rheum Dis (2017) 76:227-34. doi:10.1136/annrheumdis-2015-208456

Conflict of Interest Statement: The authors declare that the research was conducted in the absence of any commercial or financial relationships that could be construed as a potential conflict of interest.

Copyright (c) 2017 Barbera Betancourt, Lyu, Broere, Sijts, Rutten and van Eden. This is an open-access article distributed under the terms of the Creative Commons Attribution License (CC BY). The use, distribution or reproduction in other forums is permitted, provided the original author(s) or licensor are credited and that the original publication in this journal is cited, in accordance with accepted academic practice. No use, distribution or reproduction is permitted which does not comply with these terms. 